\title{
SISTEM PENDUKUNG KEPUTUSAN PENENTUAN HARGA BELI HANDPHONE BEKAS DENGAN PENERAPAN METODE FUZZY TSUKAMOTO
}

\author{
Rezky Izzatul Yazidah Anwar \\ Fakultas Teknologi Informasi \\ Universitas Islam Kalimantan Muhammad Arsyad Al Banjari Banjarmasin \\ Rezky.izzatul@gmail.com
}

\begin{abstract}
ABSTRAK
Penelitian ini didasarkan pada banyaknya penelitian yang telah dilakukan menggunakan Algoritma Backpropagation yang digunakan untuk mengenali citra berupa character recognition, objek recognition dan face recognition yang dapat mengenali dengan baik dan mendapatkan tingkat akurasi yang tinggi. Oleh karena itu penulis ingin menerapkan algoritma tersebut untuk pengenalan citra berupa simbol rambu-rambu lalu lintas agar nantinya dapat diterapkan pada mobil cerdas, sehingga dapat mengenali dan memberitahukan keadaan medan jalan yang akan dilalui oleh pengemudi.Penerapan algoritma backpropagation pada Jaringan Saraf Tiruan ini menggunakan webcam sebagai perangkat keras pengambil citra simbol rambu-rambu lalu lintas yang akan diujikan secara realtime. Untuk proses pelatihan jaringan saraf tiruannya akan digunakan 10 kelas citra simbol rambu-rambu lalu lintas yang memiliki 10 variasi pada setiap kelasnya. Proses pelatihannya menggunakan traingdx yang sudah disediakan pada matlab. Jaringan sarafnya memiliki 10 neuron 1 output, 1 input wieght, 1 layer weight, dengan ferforma trainning sse, nilai goal 0,1, batas maksimal epochs sebanyak 5000 iteration dan menggunakan 2 bias vektor. Pengujiannya menggunakan image processing berupa crop, grayscale, treshold bw (biner) dan ektraktion dengan strel (square).Hasil penelitian menunjukkan jaringan saraf tiruan dengan algoritma backpropagation menghasilkan tingkat akurasi untuk mengenali citra yang diambil menggunakan webcam secara realtime rata-rata sebesar $80 \%$ pada pengujian citra per kelas, dan 86,18\% pada saat pengujian dengan banyak 9 objek sekaligus.
\end{abstract}

Kata Kunci : fuzzy tsukamoto,penentuan harga beli, handphone, sistem pendukung keputusan.

\section{PENDAHULUAN}

Melihat perkembangan handphone yang sangat pesat, maka banyak orang mulai tertarik menekuni bisnis penjualan handphone. Permintaan konsumen akan tipe handphone terbaru selalu tinggi. Dalam beberapa tahun terakhir bisnis penjualan handphone menjadi bisnis yang sangat menjanjikan. Sehingga persaingan bisnis penjualan handphone menjadi hal yang tidak dapat dihindarkan lagi.

Tidak hanya permintaan handphone baru yang selalu tinggi tetapi kebutuhan akan telekomunikasi juga membuat handphone bekas menjadi suatu alternatif bagi konsumen. Maka toko handphone pun banyak menyediakan handphone bekas untuk memenuhi kebutuhan konsumen.

Tetapi dalam pembelian handphone bekas, karena tidak melihat pada harga pasaran maka toko handphone sering mengalami kerugian dalam penjualan kembali handphone tersebut dikarenakan salah prediksi harga beli sewaktu pembelian handphone bekas tersebut, seperti data yang terlampir dalam lampiran penelitian ini. Toko handphone juga sering mengalami kesulitan dalam menentukan harga beli handphone bekas karena sulitnya menilai kondisi dari handphone serta sulitnya menentukan harga yang layak untuk pembelian handphone tersebut. Maka untuk melakukan penilaian serta 
penentuan yang bersifat tidak jelas atau kabur seperti kasus ini, maka diperlukan sebuah metode yang bisa memecahkan masalah itu. Untuk menghitung penentuan yang bersifat kabur tersebut maka logika fuzzy adalah metode yang paling tepat untuk memetakan sebuah masalah penentuan harga beli handphone bekas.

Oleh karena itu, dibangunlah sebuah aplikasi Sistem Pendukung Keputusan Penentuan Harga Beli Handphone Bekas Dengan Penerapan Metode Fuzzy Tsukamoto sebagai suatu alternatif solusi untuk rekomendasi dalam pembelian handphone bekas.

\section{RUMUSAN MASALAH}

Bagaimana membangun program aplikasi untuk penentuan harga beli handphone bekas

\section{METODE PENELITIAN \\ Metode Pengumpulan Data}

Dalam penelitian ini diasumsikan bahwa kondisi handphone dan peminat pada dasarnya menentukan harga beli. Jadi dua parameter tersebut akan dijadikan sebagai masukan untuk sistem yang sedang dibangun. Dengan bantuan wawancara dengan pegawai toko handphone, maka dapat dijelaskan parameter untuk fuzzification input dan output sebagai berikut:

1. Kondisi handphone mempunyai 3 himpunan (Kurang, Sedang, Baik ).

2. Peminat mempunyai 3 himpunan (kurang, sedang, tinggi ).

3. Aksesoris mempunyai 2 himpunan (kurang, lengkap).

4. Harga Beli mempunyai 5 himpunan ( Murah, Mahal ).

Menentukan fungsi keanggotaan himpunan fuzzy :

a. Variabel Kondisi Handphone

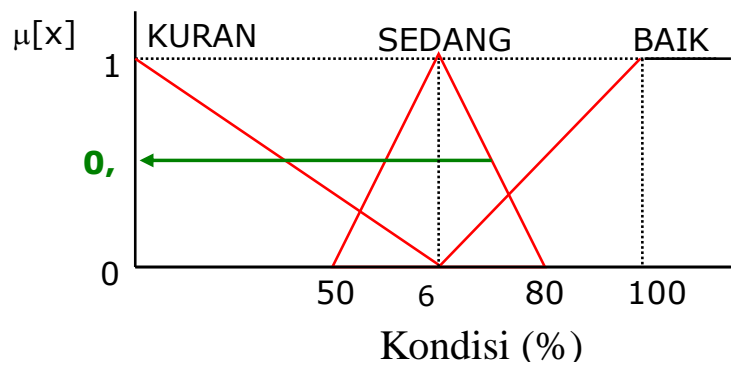

Gambar 1 Himpunan Fuzzy Variabel Kondisi Handphone menggunakan metode fuzzy tsukamoto agar dapat menjadi pertimbangan dalam membeli handphone bekas.

\section{TARGET LUARAN DAN MANFAAT PENELITIAN}

Target luaran dari penelitian ini adalah menghasilkan sebuah aplikasi yang bisa memberikan sebuah penilaian handphone bekas untuk penentuan harga beli handphone bekas.

Adapun manfaat yang diharapkan pada pembuatan tugas akhir ini adalah diharapkan dengan adanya aplikasi ini dapat merekomendasikan harga beli handphone bekas kepada para pegawainya agar mempermudah dan mempercepat penentuan harga beli handphone bekas.

Menentukan derajat keanggotaan himpunan fuzzy variabel Kondisi handphone dapat dirumuskan sebagai berikut:

$$
\begin{aligned}
& \mu[\text { Kurang }]= \begin{cases}\frac{60-x}{60}, & 0 \leq x \leq 60 \\
0, & x \geq 60\end{cases} \\
& \mu[\text { Sedang }]=\left\{\begin{array}{lll}
0 & , & x \leq 50 \text { atau } x \geq 60 \\
\frac{x-50}{60-50} & , & 50 \leq x \leq 60 \\
\frac{80-x}{80-60} & , & 60 \leq x \leq 80
\end{array}\right. \\
& \mu\left[\text { Baik] }= \begin{cases}0, & x \leq 60 \\
\frac{x-60}{100-60}, & 60 \leq x \leq 100\end{cases} \right.
\end{aligned}
$$

b. Variabel Peminat

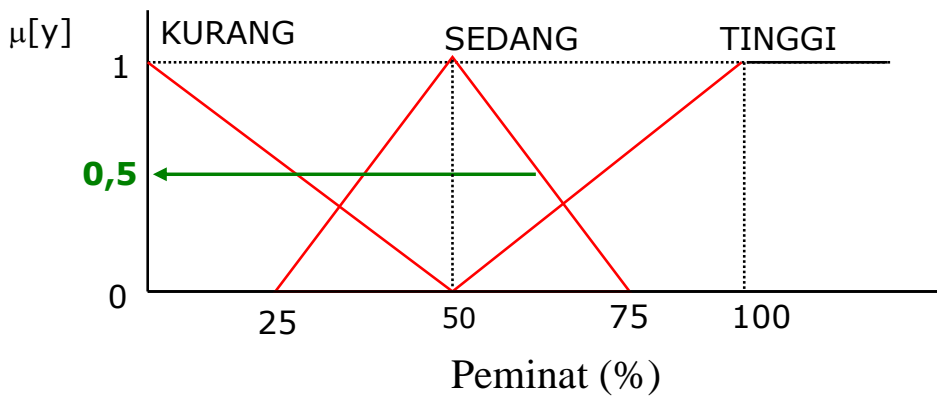

Gambar 2 Himpunan Fuzzy Variabel Peminat

Menentukan derajat keanggotaan himpunan fuzzy variabel Peminat dapat dirumuskan sebagai berikut: 
$\mathbb{A}[$ Kur ang $]= \begin{cases}\frac{50-y}{50}, & , \quad 0 \leq y \leq 50 \\ 0 & , \quad y \geq 50\end{cases}$

$(0, y \leq 25$ atau $y \geq 75$

$\mu[$ Sedang $]= \begin{cases}\frac{y-25}{50-25} & , \quad 25 \leq y \leq 50 \\ \frac{75-y}{75-50} & , \quad 50 \leq y \leq 75\end{cases}$

H[Tingil $]= \begin{cases}0, & y \leq 50 \\ \frac{y-50}{100-50}, & 50 \leq y \leq 100\end{cases}$

c. Variabel Aksesoris

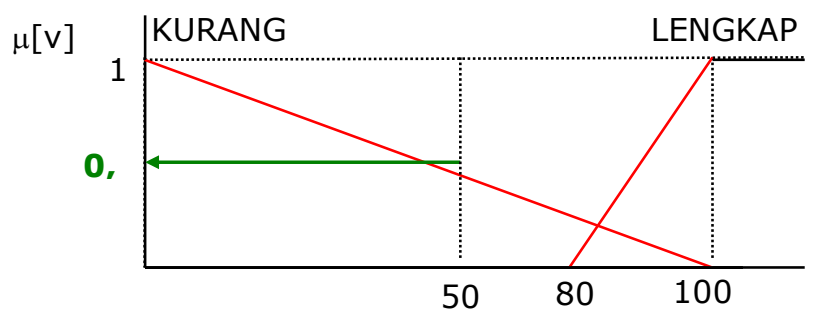

Aksesoris (\%)

Gambar 3 Himpunan Fuzzy Variabel Output Harga Beli

Menentukan derajat keanggotaan himpunan fuzzy variabel Aksesoris dapat dirumuskan sebagai berikut:

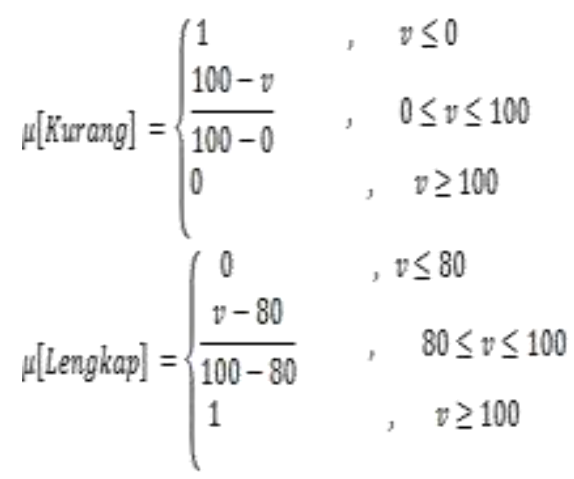

d. Variabel Harga Beli

Menentukan derajat keanggotaan himpunan fuzzy variabel Harga beli dapat dirumuskan sebagai berikut:

$$
\begin{aligned}
& \mu[\text { Murah }]= \begin{cases}1, & z \leq 10 \\
\frac{115-z}{115-10}, & , \quad 10 \leq z \leq 115 \\
0, & z \geq 115\end{cases} \\
& \text { M[Mahal] }= \begin{cases}0, & z \leq 45 \\
z-45 & , \quad 45 \leq z \leq 150 \\
150-45 & , \quad z \geq 150\end{cases}
\end{aligned}
$$

Menyusun aturan (rule). pada bagian anteseden mempunyai lebih dari satu pernyataan, maka akan menggunakan operator pendukung (disini digunakan operator $\underline{\text { AND)}}$.

\section{Diagram Konteks}

Diagram konteks memberikan gambaran umum mengenai interaksi yang terjadi antara sistem, dan user. Diagram konteks dari sistem ini ditunjukan pada gambar 4. Pada diagram konteks digambarkan proses umum yang terjadi di dalam sistem. Terdapat komponen utama yaitu user. User dapat memasukkan data handphone, data harga pasaran dan data kriteria kepada sistem, dan juga dapat melihat daftar handphone, daftar harga pasaran, dan informasi harga beli yang kemudian akan memberikan output berupa harga beli handphone yang tepat untuk user.

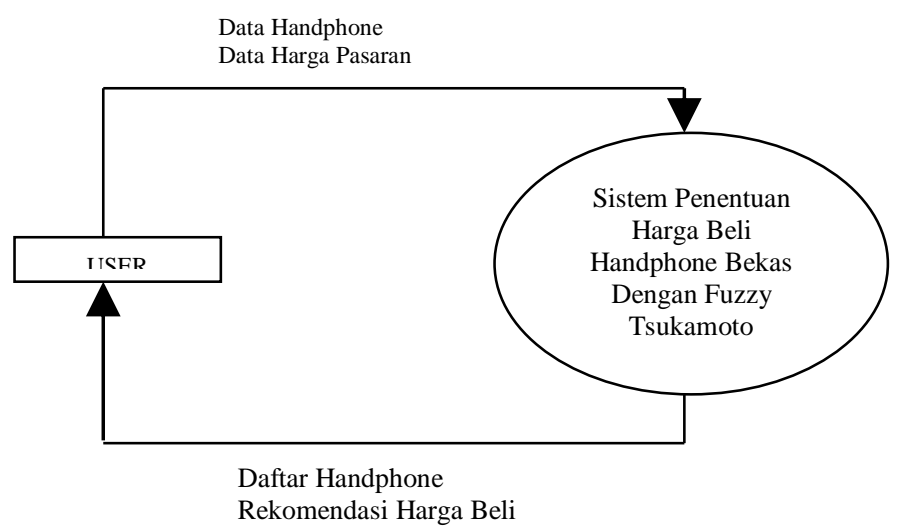

Gambar 4 Diagram Konteks 


\section{HASIL DAN PEMBAHASAN Hasil Penelitian}

a Penelitian dilakukan dengan menginput data handphone dan data harga pasaran yang dimasukkan ke dalam aplikasi Sistem Penentuan Harga Beli Handphone Bekas Dengan Fuzzy Tsukamoto

b Dari data yang telah dibuat, kemudian diolah user accepted untuk mengetahui kelayakan aplikasi yang di olah. Pengujian User Acceptance dilakukan pada penelitian ini agar mengetahui bahwa aplikasi yang telah dibuat ini layak digunakan atau justru

\section{Pembahasan}

a. Pengujian white box digunakan untuk mengetahui cara kerja suatu perangkat lunak secara internal. Pengujian dilakukan untuk menjamin operasi - operasi internal sesuai dengan spesifikasi yang telah ditetapkan dengan menggunakan struktur kendali dari prosedur yang dirancang. Dalam hal ini, pengujian tidak dilakukan terhadap keseluruhan program tetapi hanya dilakukan pada sampel pengujian untuk seleksi harga beli handphone.

b. Pengujian black box digunakan untuk menguji fungsi-fungsi khusus dari perangkat lunak yang dirancang. Pada teknik pengujian black box kebenaran perangkat luank yang diuji hanya dilihat berdasarkan keluaran yang dihasilkan dari data atau kondisi masukan yang diberikan untuk fungsi yang ada tanpa melihat bagaimana proses untuk mendapatkan keluaran tersebut. memiliki banyak kekurangan. Pengujian User Acceptance merupakan pengujian yang dilakukan secara objektif dimana aplikasi diuji dengan membuat kuesioner mengenai kepuasan user dengan kandungan point syarat user friendly.

c Setelah itu maka akan dilakukan evalusi terhadap software melalui pengujian Pre test dan Post test untuk mengetahui seberapa pengaruhnya metode Fuzzi Stukamoto menentukan harga beli handphone bekas. Sehingga didapatkannya perengkingan dengan akurasi yang baik.

c. Aplikasi yang telah dibuat ini layak atau masih memiliki banyak kekurangan.

d. Pengujian User Acceptance ini menggunakan kuisioner yang diberikan kepada 6 responden berdasarkan model skala likert (lima pilihan jawaban)

1. Apakah anda setuju tampilan tatapmuka aplikasi ini sudah user frendly dan mudah digunakan?

2. Apakah anda setuju aplikasi ini dapat membantu anda dalam melakukan penentuan harga beli handphone bekas?

3. Apakah sistem aplikasi ini lebih mudah digunakan daripada sistem manual?

4. Output yang dihasilkan apakah sudah cukup memberikan informasi?

5. Apakah anda setuju dengan aplikasi penentuan harga beli handphone bekas yang diberikan sudah tepat dan dapat diterima?

Tabel 1. Tabel Hasil Kuisioner

\begin{tabular}{|c|c|c|c|c|c|}
\hline \multirow[b]{2}{*}{ No } & \multirow[b]{2}{*}{ Pertanyaan } & \multicolumn{4}{|c|}{ Jumlah Persentase } \\
\hline & & $\begin{array}{l}\text { Sangat } \\
\text { setuju }\end{array}$ & Setuju & $\begin{array}{l}\text { Tidak } \\
\text { setuju }\end{array}$ & $\begin{array}{c}\text { Sangat } \\
\text { tidak } \\
\text { setuju }\end{array}$ \\
\hline 1 & $\mathrm{Ke}-1$ & $(7 / 7) * 100 \%=100 \%$ & - & - & - \\
\hline 2 & $\mathrm{Ke}-2$ & $(5 / 7) * 100 \%=71.4 \%$ & $(2 / 7) * 100 \%=28.6 \%$ & - & - \\
\hline 3 & $\mathrm{Ke}-3$ & $(7 / 7) * 100 \%=100 \%$ & - & - & - \\
\hline 4 & $\mathrm{Ke}-4$ & $(7 / 7) * 100 \%=100 \%$ & - & - & - \\
\hline 5 & $\mathrm{Ke}-5$ & $(4 / 7) * 100 \%=57.1 \%$ & $(3 / 7) * 100 \%=42.9 \%$ & - & - \\
\hline
\end{tabular}


Didapat nilai Alpha Cronbach adalah 0,654 dengan jumlah pertanyaan 5 buah. Alpha Cronbach $=0,654$ terletak antara 0,60 hingga 0,80 sehingga tingkat reliabilitasnya reliable.

Tabel 2. Tingkat Reliabilitas berdasarkan Nilai Alpha

\begin{tabular}{|c|c|}
\hline Alpha & Tingkat Reliabilitas \\
\hline $0,00 \mathrm{~s} / \mathrm{d} 0,20$ & Kurang Reliabel \\
\hline$>0,20 \mathrm{~s} / \mathrm{d} 0,40$ & Agak Reliabel \\
\hline
\end{tabular}

Dari semua hasil pengujian yang telah dilakukan dari pengujian validitas maupun reliabilitas menunjukkan bahwa pengujian User Acceptance ini telah menghasilkan data yang valid dengan tingkat reabilitasnya termasuk Reliabel.

Berdasarkan hasil uji keakuratan penentuan harga beli handphone bekas secara manual di lapangan (pretest) dan hasil penentuan harga beli handphone bekas pada aplikasi sistem pendukung keputusan (posttest),
Untuk lebih jelasnya tingkat reabilitas berdasarkan nilai Alpha dapat dilihat pada tabel dibawah ini.

\begin{tabular}{|c|l|}
\hline$>0,40 \mathrm{~s} / \mathrm{d} 0,60$ & Cukup Reliabel \\
\hline$>0,60 \mathrm{~s} / \mathrm{d} 0,80$ & Reliabel \\
\hline $0,80 \mathrm{~s} / \mathrm{d} 1,00$ & Sangat Reliabel \\
\hline
\end{tabular}

dapat dicari presentase dari nilai keakuratannya dengan rumus sebagai berikut :

$$
\text { akurasi }=\frac{\text { jumlah data dengan selisih menguntungkan }}{\text { jumlah data yang diuji }} * 100 \%
$$

Untuk hasil dari nilai keakuratan data pretest dan posttest dapat dilihat pada tabel berikut :

Tabel 3. Perbandingan Pretest dan Posttest

\begin{tabular}{|c|c|c|c|c|c|c|}
\hline \multirow[b]{2}{*}{ No. } & \multirow{2}{*}{ Merk } & \multirow{2}{*}{ Type } & \multicolumn{2}{|c|}{ Kesesuaian Harga Beli } & \multicolumn{2}{|c|}{ Nilai Keakuratan } \\
\hline & & & Pretest & Posttest & Pretest & Posttest \\
\hline 1 & NOKIA & C1-01 & Tidak sesuai & Sesuai & 0 & 1 \\
\hline 2 & NOKIA & C1-01 & Sesuai & Sesuai & 1 & 1 \\
\hline 3 & NOKIA & C1-01 & Sesuai & Sesuai & 1 & 1 \\
\hline 4 & NOKIA & C2-01 & Tidak sesuai & Sesuai & 0 & 1 \\
\hline 5 & NOKIA & C3 & Sesuai & Sesuai & 1 & 1 \\
\hline 6 & NOKIA & C3 & Tidak sesuai & Sesuai & 0 & 1 \\
\hline 7 & NOKIA & $\mathrm{C} 3$ & Sesuai & Sesuai & 1 & 1 \\
\hline 8 & NOKIA & C6 & Tidak sesuai & Sesuai & 0 & 1 \\
\hline 9 & NOKIA & E52 & Tidak sesuai & Sesuai & 0 & 1 \\
\hline 10 & NOKIA & E52 & Tidak sesuai & Sesuai & 0 & 1 \\
\hline 11 & NOKIA & E63 & Tidak sesuai & Sesuai & 0 & 1 \\
\hline 12 & NOKIA & E63 & Sesuai & Sesuai & 1 & 1 \\
\hline 13 & NOKIA & E63 & Sesuai & Sesuai & 1 & 1 \\
\hline 14 & NOKIA & E63 & Tidak sesuai & Sesuai & 0 & 1 \\
\hline 15 & NOKIA & E63 & Sesuai & Sesuai & 1 & 1 \\
\hline 16 & NOKIA & E71 & Sesuai & Sesuai & 1 & 1 \\
\hline 17 & NOKIA & E71 & Tidak sesuai & Sesuai & 0 & 1 \\
\hline
\end{tabular}




\begin{tabular}{|c|c|c|c|c|c|c|}
\hline 18 & NOKIA & N5130 & Tidak sesuai & Sesuai & 0 & 1 \\
\hline 19 & NOKIA & N5220 & Sesuai & Sesuai & 1 & 1 \\
\hline 20 & NOKIA & N5800 & Tidak sesuai & Sesuai & 0 & 1 \\
\hline 21 & NOKIA & N5800 & Tidak sesuai & Sesuai & 0 & 1 \\
\hline 22 & NOKIA & N97 & Sesuai & Sesuai & 1 & 1 \\
\hline 23 & NOKIA & $\mathrm{X} 2$ & Sesuai & Sesuai & 1 & 1 \\
\hline 24 & NOKIA & $\mathrm{X} 2-01$ & Tidak sesuai & Sesuai & 0 & 1 \\
\hline 25 & NOKIA & $\mathrm{X} 2-01$ & Sesuai & Sesuai & 1 & 1 \\
\hline 26 & NOKIA & $\mathrm{X} 2-01$ & Sesuai & Sesuai & 1 & 1 \\
\hline 27 & NOKIA & $\mathrm{X} 2-02$ & Tidak sesuai & Sesuai & 0 & 1 \\
\hline 28 & NOKIA & X3 & Tidak sesuai & Sesuai & 0 & 1 \\
\hline 29 & NOKIA & X3 & Sesuai & Sesuai & 1 & 1 \\
\hline 30 & NOKIA & X3-02 & Sesuai & Tidak sesuai & 1 & 0 \\
\hline 31 & NOKIA & $\mathrm{X} 5$ & Sesuai & Sesuai & 1 & 1 \\
\hline 32 & SAMSUNG & B3310 & Tidak sesuai & Sesuai & 0 & 1 \\
\hline 33 & SAMSUNG & Champ & Sesuai & Sesuai & 1 & 1 \\
\hline 34 & SAMSUNG & Champ & Sesuai & Sesuai & 1 & 1 \\
\hline 35 & SAMSUNG & Chat & Tidak sesuai & Sesuai & 0 & 1 \\
\hline 36 & SAMSUNG & Chat & Sesuai & Sesuai & 1 & 1 \\
\hline 37 & SAMSUNG & Chat & Sesuai & Sesuai & 1 & 1 \\
\hline 38 & SAMSUNG & Galaxy Ace & Sesuai & Sesuai & 1 & 1 \\
\hline 39 & SAMSUNG & Galaxy Fit & Tidak sesuai & Sesuai & 0 & 1 \\
\hline 40 & SAMSUNG & Galaxy Mini & Sesuai & Tidak sesuai & 1 & 0 \\
\hline \multicolumn{5}{|c|}{ Jumlah } & 22 & 38 \\
\hline \multicolumn{5}{|c|}{ Rata-rata Keakuratan } & 0,55 & 0,95 \\
\hline \multicolumn{5}{|c|}{ Persentase Keakuratan Harga Beli } & 55 & 95 \\
\hline
\end{tabular}

\section{Kesimpulan}

Dengan menggunakan fuzzy tsukamoto prediksi yang dihasilkan bukanlah prediksi asal yang tidak berdasar. Hasil dari fuzzy tsukamoto adalah berupa angka taksiran berdasarkan perhitungan matematis sehingga tingkat keakuratannya pun bisa diukur.

Berdasarkan hasil yang diperoleh maka dapat diambil kesimpulan:

1. Metode fuzzy tsukamoto dapat digunakan untuk menentukan harga beli handphone bekas.

2. Sesuai atau tidak hasil perhitungan fuzzy tsukamoto dengan kondisi pasar sangat dipengaruhi oleh kondisi handphone tersebut

\section{Saran}

Saran yang dapat disampaikan dalam pengembangan aplikasi ini adalah:

1. Sistem yang dibuat masih sangat sederhana, untuk kedepannya mungkin bisa ditambahkan fasilitas alarm pengingat update harga pasaran secara berkala.

2. Perlu ditambah untuk pengaturan tambah variabel input dan output.

3. Karna banyak toko handphone yang mempunyai cabang, bisa dikembangkan ke arah multi user atau bahkan dalam bentuk web untuk jaringan yang lebih luas 


\section{DAFTAR PUSTAKA}

Abdurrahman, G. (2011). Penerapan Metode Tsukamoto (Logika Fuzzy) Dalam Sistem Pendukung Keputusan Untuk Menentukan Jumlah Produksi Barang Berdasarkan Data Persediaan Dan Jumlah Permintaan. Yogyakarta: Universitas Negeri Yogyakarta.

Ahyadi, Z. (2010). Experimental Analysis on ECC Schemes for FaultTolerant Hybrid Memories. Netherlands: Delft University of Technology.

Ilmawati, M. (2008). Sistem Pendukung Keputusan Pemilihan Harga Jual Handphone Dengan Metode Game Theory. Surabaya: STIKOM Surabaya.

Irwanto, Djon. (2006). Perancangan Object Oriented Software dengan UML. Yogyakarta: Andi Publisher.

Kusrini, \& Koniyo, A. (2007). Tuntunan Praktis Membangun Sistem Informasi Akuntansi dengan Visual Basic dan Microsoft SQL Server. Yogyakarta: Penerbit Andi.

Kusumadewi, S., \& Hartati, S. (2010). Neuro-Fuzzy Integrasi Sistem Fuzzy \& JAringan Syaraf Ed 2. Yogyakarta: GRAHA ILMU.

Kusumadewi, S., \& Purnomo, H. (2010). Aplikasi Logika Fuzzy untuk Pendukung Keputusan Ed 2. Yogyakarta: GRAHA ILMU.

Laudon, K. C., \& Laudon, J. P. (2008). Sistem Informasi Manajemen: Mengelola Perusahaan Digital 2 Edisi 10. Jakarta: Salemba Empat.

Madcoms. (2007). Pemrograman Borland Delphi 7. Yogyakarta: Andi.

Marshal, Y. A. (2010). Pengujian Stenografi untuk Compresser Data. Bandung: Institut Teknologi Bandung.
Nugroho, A. (2010). Rekaya Perangkat Lunak Berorientasi Objek dengan Metode USDP. Yogyakarta: Penerbit Andi.

Nugroho, A. (2010). Rekayasa Perangkat Lunak Menggunakan UML dan JAVA . Jakarta: Andi Publisher.

Sklar, B. (2001, Pebruari 01). Reed Solomon Codes. Retrieved April 03, 2011, from BahanSkripsi: www.bahanskripsi.info

Soeherman, B., \& Pinontoan, M. (2008). Designing Information System. Jakarta: Elex Media Komputindo.

Supriyanto, W., \& Muhsinin, A. (2008). Teknologi Informasi perpustakaan. Yogyakarta: Penerbit Kanisius.

Sutabri, T. (2010). Sistem Informasi Manajemen . Jakarta: Andi Publisher.

Tervo, R. (2010, Maret 08). Introduction Reed Solomon Codes. Retrieved April 10, 2011, from UNB: www.ee.unb.ca

Wahana, K. (2011). PANDUAN APLIKATIF \& SOLUSI APLIKASI CERDAS MENGGUNAKAN DELPHI . Yogyakarta: Andi Publisher .

Wahyono, T. (2010). Membuat sendiri aplikasi dengan memanfaatkan barcode. Jakarta: Elex Media Komputindo.

Wahyu W., R., \& Afriyanti, L. (2009). aplikasi fuzzy inference system (fis) metode tsukamoto pada simulasi traffic light menggunakan java . Seminar Nasional Aplikasi Teknologi Informasi 2009 (SNATI 2009) I, 1.

Wulandari, S. (2010). APLIKASI PROSES HIERARKI ANALITIK (PHA) DALAM MEMILIH HANDPHONE. Bandung: Universitas Pendidikan Indonesia. 